\section{Perfectly personal dentures}

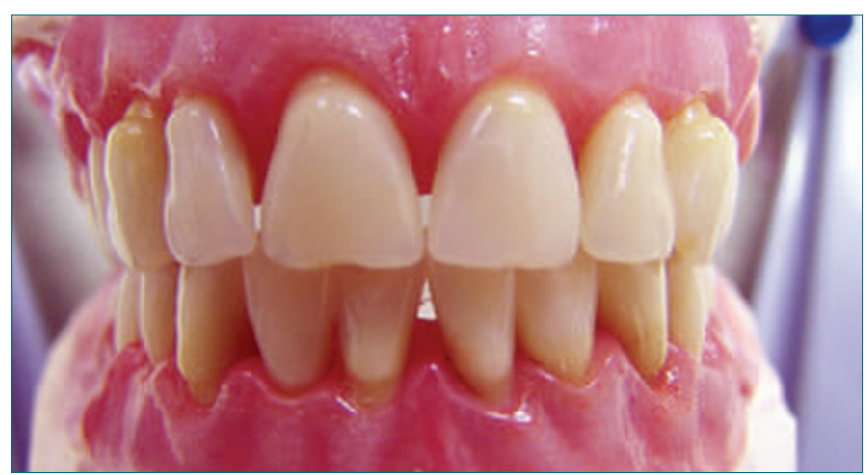

To help you market your private dentures, Myerson, suppliers of convincingly realistic private denture teeth, supply a marketing pack free of charge. The pack includes a shade guide, before and after glossy photographs laminated on card, patient brochures and a mould chart.

To help you to personalise your patients' dentures, the Living Mould Guide has actual samples of each of the upper anterior teeth so you will be able to exactly match not only the shade of the natural teeth but also show patients the best match in terms of texture and translucency. The guide usually costs $£ 324$, but as a special promotion is offered at $\mathfrak{£} 115$. Call 02088639044 for more details.

\section{Ultimate infection control}

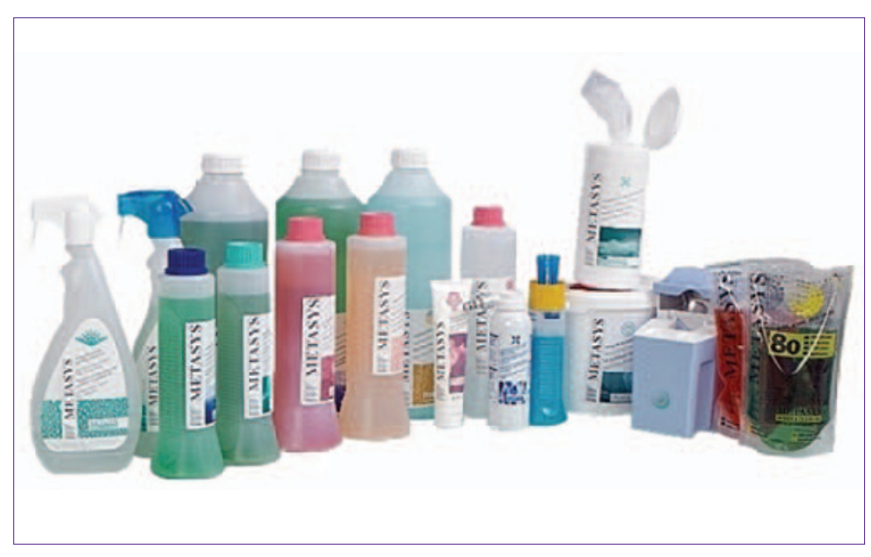

Metasys' Green\&Clean range of hygiene products provides you with the highest possible level of infection control. With numerous products within the range, you will find the solution that you are looking for, whether it's alcohol-free and suitable for delicate surfaces, or a highly concentrated cost saving product.

All disinfectants from Metasys are biodegradable and therefore environmentally friendly, and each disinfectant has a CE sign. Metasys supply a range of information posters that can be displayed in the practice and can be particularly useful as a reminder to staff. For more information on the range of products call 08458381636 or visit www.metasys.com.

\section{Tailor-made surgery art}
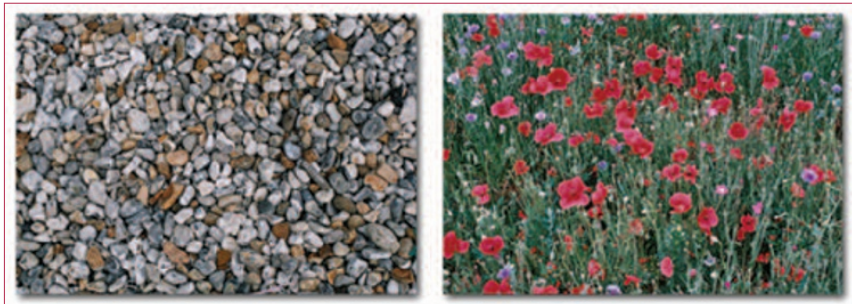

Designer Dental has announced the addition of a new dimension to their poster, print and canvas portfolio. The new prints are exclusive to Designer Dental and have been taken from original photographs by dentist Chris May. These prints do not have a dental theme; they are purely decorative and pleasing to look at and can be purchased individually or in matching pairs. They come in three standard sizes, or if you prefer, can be tailor-made to any size you wish. Contact 01642206106 or visit at www. designerdental.co.uk for more details.

\section{Eliminate misunderstanding}

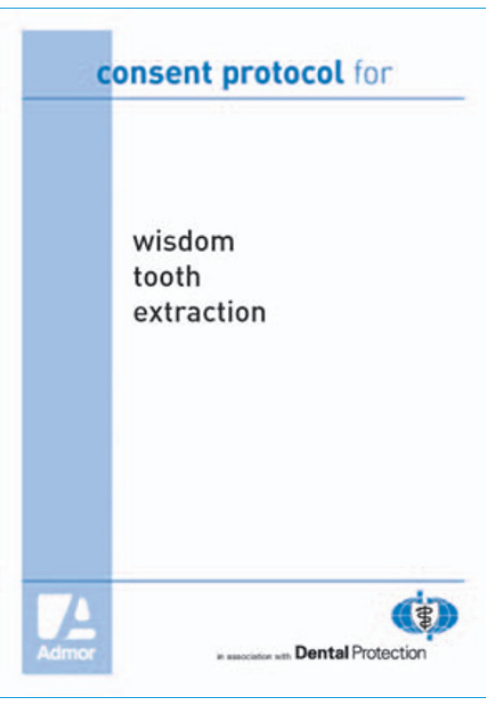

Admor, in association with Dental Protection, offer a unique range of practical treatment consent forms These forms have been designed to help both dentists and patients establish consent before treatment commences, helping to eliminate any future misunderstandings.

Presented in pad format, a new document can be generated for each patient. The pages provide general instructions for the dentist to ensure consent is gained in an appropriate manner, and general information for patients explaining why the procedure is necessary at all, along with information on the upcoming procedure, advice before and after treatment and consultation record patient and dentist copies.

The forms are intended to provide the dentist with a checklist of issues that need to be discussed, provide patients with pre- and post-treatment advice, and also to provide a record of the patient's agreement and understanding. For more information on the range of products available from Admor, call 01243553078 or visit www.admor.co.uk. 